\title{
Trends of geographic inequalities in the distribution of human resources in healthcare system: the case of Iran
}

\section{Sara Emamgholipour Sefiddashti ${ }^{1}$, Mohammad Arab $^{2}$, Sadegh Ghazanfari ${ }^{3}$, Zhila Kazemi ${ }^{4}$, Satar Rezaei ${ }^{5}$, Ali} Kazemi Karyani ${ }^{5,6}$

${ }^{1}$ Ph.D., Assistant Professor, Department of Health Management and Economics, School of Public Health, Tehran University of Medical Sciences, Tehran, Iran

${ }^{2}$ Ph.D. of Health Services Management, Professor, Department of Health Management and Economics, School of Public Health, Tehran University of Medical Sciences, Tehran, Iran

${ }^{3}$ Ph.D. Student in Health Economics, Health Management and Economics Research Center, Iran University of Medical Sciences, Tehran, Iran

${ }^{4}$ M.Sc. in Medical Informatics, Research Center for Environmental Determinants of Health, Kermanshah University of Medical Sciences, Kermanshah, Iran

${ }^{5}$ Ph.D. Student in Health Economics, Research Center for Environmental Determinants of Health, Kermanshah University of Medical Sciences, Kermanshah, Iran

${ }^{6} \mathrm{Ph} . \mathrm{D}$. Student in Health economics, Department of Health Management and Economics, School of Public Health, Tehran University of Medical Sciences, Tehran, Iran

Type of article: Original

\begin{abstract}
Introduction: Considering the scarcity of skilled workers in the health sector, the appropriate distribution of human resources in this sector is very important for improving people's health. Having information about the degree of equality in the distribution of health human resources and their time trends is necessary for better planning and efficient use of these resources. The aim of this study was to determine the trend of inequality in the allocation of human resources in the health sector in Tehran between 2007 and 2013.

Methods: This cross-sectional study was conducted in Tehran Province in Iran. The inequality in the distribution of human resources (specialists, general practitioners, pharmacists, paramedics, dentists, nurses and community health workers (Behvarz)) in 10 cities in Tehran Province was investigated using the Gini coefficient and the dissimilarity index. The time trend of inequality was examined by regression analysis. The required data were collected from the statistical yearbook of the Iran Statistics Center (ISC).

Results: The highest value of the Gini coefficient $(\mathrm{GC})$ was related to nurses $(\mathrm{GC}=0.291)$ in 2007. The highest value of the Gini coefficient was related to nurses and Behvarzs in 2008 and 2009, respectively. The distribution of specialists had the highest inequality in $2010(\mathrm{GC}=0.298), 2011(\mathrm{GC}=0.300)$ and $2013(\mathrm{GC}=0.316)$. General practitioners had the lowest Gini coefficient for 2007, 2008 and 2012. Nurses for 2009 and Behvarzs for 2010, 2011 and 2013 had the lowest value of Gini coefficient. The dissimilarity indexes for specialists and general practitioners were 26.64 and 8.72 in 2013 , respectively. The means of this index for included resources were 31.35 , $18.27,16.91,22.32,15.82,26.74$, and 24.33 , respectively. The time trend analysis showed that the coefficient of time was positive for all of the human resources, except Behvarzes, and only the coefficient of general practitioners was statistically significant $(\mathrm{p}<0.01)$.

Conclusion: Over time, inequalities in the distribution of resources in the health sector have been increasing. By developing the private sector and considering the trend of this sector to operate in the more developed regions, health policy makers should continually evaluate the distribution of human resources, and they should arrange a specific plan for the allocation of human resources in the health sector.
\end{abstract}

Keywords: Inequality, Human Resources, Gini coefficient, Dissimilarity index, Tehran Province, Iran

\section{Corresponding author:}

Ali Kazemi Karyani, Research Center for Environmental Determinants of Health, Kermanshah University of Medical Sciences, Kermanshah, Iran. Tel: +98.9183558225, E-mail: alikazemi2000@yahoo.com

Received: September 16, 2015, Accepted: April 04, 2016, Published: July 2016

iThenticate screening: April 04, 2016, English editing: May 17, 2016, Quality control: July 04, 2016

(C) 2016 The Authors. This is an open access article under the terms of the Creative Commons Attribution-NonCommercialNoDerivs License, which permits use and distribution in any medium, provided the original work is properly cited, the use is noncommercial and no modifications or adaptations are made. 


\section{Introduction}

Economic development is considered as one of the main goals of any country because it results in increasing the prosperity of the nation. Natural resources, human resources, capital, and technology are some of the factors in economic growth. One of the most important resources for the development of any society is manpower, and most management pundits believe that human resources are the only competitive advantage and that communities should take appropriate and proper actions in order to convert this potential force into an actual force for the purposes of the society (1-3). Considering that one of the factors that affect the productivity of human resources and avoid wasting these forces is their appropriate distribution, i.e., this valuable resource must be effectively and equitably distributed to achieve appropriate productivity in the workforce. The health sector, which is considered as a support for community health, relies on human resources more than other sectors so that more than $10 \%$ of the government employees are devoted to this sector in most countries (4). The human resources of this sector have a major role in providing health services, and it is considered as main basis of all health systems. Therefore, the health system should determine the organization of human resources to suit the needs of society and socio-economic conditions governing it in order to reach a level of service that ensures the health of people and their ability to have useful and productive lives. The health system of each country can take an essential step in order to improve the health system through the fair distribution and efficient organization of the health-related staff. The allocation of human resources has been considered as a major challenge for many countries because of their limited human resources and the increasing complexity of health dimensions $(5,6)$. Five types of inequality in the allocation of human resources can be defined as follows: 1) inequality of expertise, 2) inequality in the distribution, 3) gender inequality, 4) inequality in organizing, and 5) inequality of public or private forces. In most countries, the main concerns about the fairness in the distribution of human resources in the health sector is more focused on the number of people allocated to each region, type, and method of distribution and the proper performance of employees (7). The distribution of human resources per capita in the sector should be investigated in order to determine the quantity of human resources in every region or the distribution of health sector workers. The education level normally has been considered as a criterion to evaluate the quality of the forces. The injustice of the quality of human resources in the different regions can be studied by evaluating the distribution of specialists with higher educational levels (8). In many cases, studies have shown that the geographical distribution of health resources, especially human resources, is not optimal in Iran (7, 9-11). Tehran Province is not an exception to this observation (12). According to current statistics, 385,667 people were employed in the Iran Ministry of Health in 2013, of which 33,428 (11.54\%) of them were employed in Tehran Province. Also, more than 12,433,000 people live in this Province, which amounts to $16.16 \%$ of Iran's total population of 76,942,000 people (13). Then, inequality in the distribution of resources in the Province could seriously affect many people who are living there, and it also can lead to inefficiency and loss of a significant portion of resources in the health sector. First, this situation should be recognized well to establish appropriate policies for the proper allocation of human resources, and then a decision should be made based on the facts. Note that the Gini coefficient is one of the best indicators that can evaluate the distribution of different resources, including human resources. In recent years, it has been used to investigate the inequality in healthcare (14-19). In this study, the Gini coefficient and the dissimilarity index were used to investigate the allocation of employed human resources in the health sector in Tehran Province between 2007 and 2013. The changes in the distribution of health human resources during this period were assessed using regression models.

\section{Material and Methods}

\subsection{Study setting}

The present study can be considered as a cross-sectional, descriptive, and practical study. In this study, the required data were collected from the statistical yearbook of the Iran Statistics Center (ISC) (13). Furthermore, the distribution of human resources in the health sector (specialists, general practitioners, pharmacists, paramedics, dentists, nurses, and community health workers (Behvarz)) was evaluated, and the inequality in the distribution of resources in the 10 cities of Tehran Province also was investigated using the Gini coefficient and the dissimilarity index between 2007 and 2013.

\subsection{Gini Coefficient}

The Gini coefficient is the most well-known index by which the distribution of resources and the class gap can be measured in different societies. The Gini coefficient, a statistical distribution unit, commonly is used to measure inequalities in the distribution of income or wealth in a statistical population (20). Health distribution or health care resource distribution also can be measured by this index. The Gini coefficient is obtained from the Lorenz curve, and it contains the area between the line of perfect equality and the Lorenz curve (9). Earlier, the Lorenz curve and the Gini coefficient had been used only in economics and the social sciences, but, in recent years, this concept also has 
been used in other areas, such as medical research and health services. One of the most common equations to calculate the Gini coefficient is as follows (21):

$$
G=\frac{1}{2 \mu N^{2}} \sum_{i=1}^{N} \sum_{j=1}^{N}\left|\mathrm{y}_{\mathrm{i}}-\mathrm{y}_{\mathrm{j}}\right|,
$$

where $G$ is the Gini coefficient, $\mu$ is the mean of the distribution, $N$ is sample size, and $Y_{i}$ is the number of human resources in the $i^{\text {th }}$ city. The Gini coefficient is a number between zero and one, with zero representing perfect equality and one representing complete inequality in the distribution of resources $(14,22)$. The Jackknife variance estimator for the Gini coefficient evaluated by the standard error can be calculated according to the following equation:

$$
\mathrm{v}=\frac{N-1}{N} \sum_{i=0}^{N}\left(\mathrm{G}_{\mathrm{i}}-\mathrm{G}\right)^{2},
$$

where $v$ is the variance estimator, $G_{i}$ is the Gini coefficient for the $i^{\text {th }}$ observation of the sample, and $N$ is the sample size $(18,23,24)$. The t-test has been used to verify the existence of inequality in the distribution of resources, which is the null hypothesis of this test. The value of t-statistic greater than 1.96 in each of the Gini coefficients implies that the null hypothesis, i.e., the existence of equality in the distribution of the resource, is rejected (in the desired year). Although the Gini coefficient is an extensively-used index, it only shows the value of inequality and does not specify the adjustments needed to achieve equality, so other indexes such as dissimilarity index must be utilized. The redistribution value required to achieve perfect equality can be determined by using this index.

\subsection{Dissimilarity Index (DI)}

The dissimilarity index is one of the inequality indexes that commonly are used in the health sector. Dissimilarity index could be determined by the following formula:

$$
D I=\frac{1}{2} \sum_{i=1}^{n}\left|\mathrm{H}_{\mathrm{ip}}-\mathrm{H}_{\mathrm{ih}}\right|,
$$

where $D I$ is the index of dissimilarity, $H_{i p}$ is the $i^{\text {th }}$ County's population share, $H_{i h}$ is the share of health human resources allocated to the $i^{\text {th }}$ county, and $n$ is the total number of counties. The values of this index are between 0 and $100 \%$. It implies that a few percent of targeted resources should be redistributed to achieve perfect equality in the distribution of resources; for example, if the index of dissimilarity is equal to $20 \%$ for specialists, $20 \%$ of the specialists should be redistributed to achieve perfect equality of this variable (25). The trend of the distribution of resources should be considered in the studies that usually review the inequality of the distribution. The question of whether inequality in distribution of skilled human resources decreased between 2007 and 2013 should be answered. The time trend of the obtained Gini coefficients can be examined using the regression model as follows (21):

$$
\text { Git }=\alpha i+\beta t+\varepsilon i,
$$

where $G_{i t}$ is the Gini coefficient for human resources from 2007 to $2013 ; t$ is time; $\varepsilon_{i}$ is the error component; and $\beta$ is the time effect coefficient. Seven regression models were fitted separately to investigate the distribution trend. The heteroscedasticity the variables of the model was examined using the Breusch-Pagan test. The $\beta$ coefficient shows both the direction and strength of the effect of time on the Gini coefficient. Therefore, the negative values of the $\beta$ coefficient indicate reductions in the Gini coefficient and reduction of the inequalities in the distribution of the desired resource. Stata version 11 and Microsoft Office Excel 2010 were used to analyze the data in this study.

\section{Results}

The abundance of employed human resources in the health and treatment sector in the urban and rural population (covered by health houses) of Tehran Province in 2013 is shown in Table 1. According to Table 1, it is obvious that paramedics are the maximum human resources employed in the health sector of Tehran Province and pharmacists are minimal. Gini coefficients for variables (human resources) are shown in Table 2. Nurses had the highest value of the Gini coefficient $(\mathrm{GC}=0.291)$ and the general practitioners had the lowest value $(\mathrm{GC}=0.264)$ in 2007. In 2008, general practitioners and nurses had the minimum and maximum values of the Gini coefficient ( 0.266 and 0.293$)$, respectively. Behvarzes had the highest value of the Gini coefficient in 2009 ( $\mathrm{GC}=0.394)$. Specialist had the highest value of the Gini coefficient $(\mathrm{GC}=0.298)$ in 2010. The distribution of specialists had the highest inequality in $2011(\mathrm{GC}=0.300)$ and $2013(\mathrm{GC}=0.316)$, too. The lowest Gini coefficient for 2008 and 2012 was related to General practitioners. The values, standard error, minimum, and maximum of Gini coefficients for different human resources employed in the health sector during the period of the study are shown in Table 2. In total, during this period, specialists and nurses had the highest inequality distribution, and Behvarz and General practitioners had the lowest inequality distribution. The Gini coefficients belong to Behvarzes had the lowest standard error in many years of studied period. In total, specialists and nurses also had the highest standard error for Gini coefficients (Table 2). 
http://www.ephysician.ir

Table 1. Availability of human resources in Tehran Province in 2013

\begin{tabular}{|l|l|l|l|l|l|l|l|l|}
\hline City & Specialist & GP & Pharmacists & Paramedics & Dentists & Nurses & Behvarzes & Population \\
\hline Eslamshahr & 0 & 31 & 13 & 240 & 18 & 9 & 33 & 490211 \\
\hline Pakdasht & 25 & 25 & 4 & 323 & 7 & 58 & 44 & 294495 \\
\hline Tehran & 3019 & 849 & 227 & 18122 & 420 & 7696 & 10 & 8363845 \\
\hline Damavand & 31 & 31 & 6 & 345 & 13 & 80 & 42 & 101598 \\
\hline Robatkarim & 29 & 55 & 12 & 514 & 15 & 114 & 25 & 728799 \\
\hline Rei & 2 & 47 & 10 & 293 & 17 & 9 & 52 & 328257 \\
\hline Shemiranat & 1 & 53 & 6 & 243 & 23 & 2 & 20 & 53772 \\
\hline Shahriar & 48 & 70 & 14 & 776 & 24 & 142 & 61 & 1301415 \\
\hline Firouzkouh & 25 & 21 & 4 & 162 & 3 & 16 & 26 & 38835 \\
\hline Varamin & 32 & 55 & 8 & 523 & 12 & 102 & 58 & 606547 \\
\hline Total & 3212 & 1237 & 304 & 21541 & 552 & 8228 & 371 & 12307774 \\
\hline Mean & 321 & 124 & 30 & 2154 & 55 & 823 & 37 & 1230777 \\
\hline S.D & 899 & 242 & 66 & 5325 & 122 & 2292 & 16 & 2405161 \\
\hline Min & 0 & 21 & 4 & 162 & 3 & 2 & 10 & 38835 \\
\hline Max & 3019 & 849 & 227 & 18122 & 420 & 7696 & 61 & 8363845 \\
\hline
\end{tabular}

GP: general practitioner

Table 2. Gini coefficient for human resources in the health system in Tehran Province, 2007-2013

\begin{tabular}{|l|l|l|l|l|l|l|l|l|l|l|}
\hline \multirow{2}{*}{$\begin{array}{l}\text { Human } \\
\text { resources }\end{array}$} & 2007 & 2008 & 2009 & 2010 & 2011 & 2012 & 2013 & $2007-2013$ \\
\cline { 2 - 10 } & GC & GC & GC & GC & GC & GC & GC & Min & Max \\
Specialists & 0.290 & 0.289 & 0.255 & 0.298 & 0.300 & 0.315 & 0.316 & 0.255 & 0.316 \\
& $(0.234)$ & $(0.232)$ & $(0.113)$ & $(0.238)$ & $(0.239)$ & $(0.246)$ & $(0.246)$ & & \\
\hline General & 0.264 & 0.266 & 0.277 & 0.276 & 0.271 & 0.288 & 0.293 & 0.264 & 0.293 \\
practitioners & $(0.204)$ & $(0.206)$ & $(0.115)$ & $(0.214)$ & $(0.208)$ & $(0.217)$ & $(0.221)$ & \\
\hline Pharmacists & 0.283 & 0.280 & 0.251 & 0.291 & 0.290 & 0.301 & 0.299 & 0.251 & 0.301 \\
& $(0.225)$ & $(0.222)$ & $(0.108)$ & $(0.231)$ & $(0.228)$ & $(0.230)$ & $(0.227)$ & & \\
\hline Paramedics & 0.279 & 0.283 & 0.251 & 0.291 & 0.291 & 0.307 & 0.308 & 0.251 & 0.308 \\
& $(0.221)$ & $(0.225)$ & $(0.110)$ & $(0.230)$ & $(0.230)$ & $(0.237)$ & $(0.237)$ & & \\
\hline Dentists & 0.279 & 0.277 & 0.239 & 0.277 & 0.278 & 0.297 & 0.302 & 0.239 & 0.302 \\
& $(0.221)$ & $(0.218)$ & $(0.106)$ & $(0.215)$ & $(0.216)$ & $(0.226)$ & $(0.230)$ & & \\
\hline Nurses & 0.291 & 0.293 & 0.228 & 0.298 & 0.298 & 0.314 & 0.315 & 0.228 & 0.315 \\
& $(0.234)$ & $(0.236)$ & $(0.109)$ & $(0.238)$ & $(0.237)$ & $(0.245)$ & $(0.245)$ & & \\
\hline Behvarzes & 0.279 & 0.280 & 0.395 & 0.242 & 0.210 & 0.328 & 0.187 & 0.187 & 0.395 \\
& $(0.027)$ & $(0.022)$ & $(0.186)$ & $(0.050)$ & $(0.041)$ & $(0.072)$ & $(0.051)$ & \\
\hline
\end{tabular}

*Standard error

The results showed that the discussed distribution of human resources has been totally increasing, but the resources, such as specialists and nurses, had more inequality (Figure 1). The values of dissimilarity indexes (DI) of distribution health human resources in Tehran Province and the mean and standard deviation (SD) of DI during the period of study are shown in Table 3. According to the table, the dissimilarity indexes for specialists and general practitioners in 2013 were 18.27 and 26.64, respectively. The averages of this index for the specialists, general practitioner, pharmacist, paramedics, dentist, nurse, and Behvarz were 31.35, 18.27, 16.91, 22.32, 15.82, 26.74, and 24.33, respectively. Minimum and maximum standard deviations of decentralization index between 2007 and 2013 belong to nurses (SD $=1.92)$ and general practitioners $(\mathrm{SD}=11.96)$. The trend of inequality in the distribution of variables during the years 2007 to 2013 are shown in Table 4. The $\beta$ coefficients for all human resources, except Behvarzes, in the health sector in Tehran Province were positive during the period, and the coefficient of general practitioners was statistically significant $(\mathrm{p}<0.01)$. The Breusch-Pagan test was used to investigate the heteroscedasticity regression models, and the zero hypothesis (constant variance) was not rejected $(\mathrm{p}>0.05)$. 


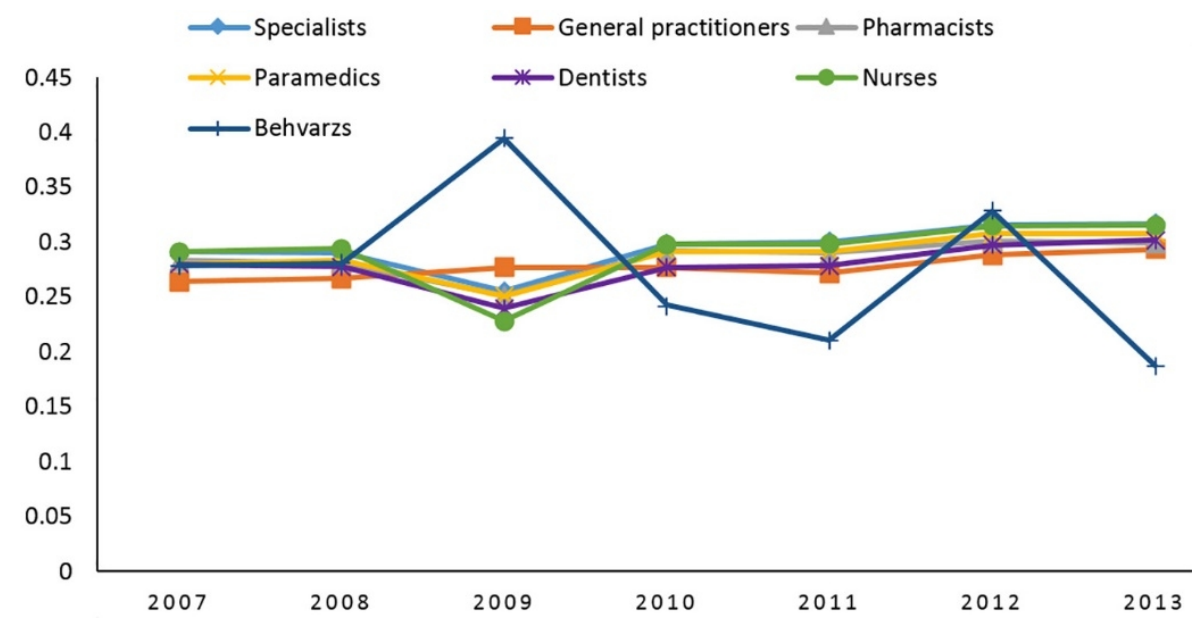

Figure 1. Trends in the Gini coefficient for the distribution of human resources in Tehran province, 2007-2013

Table 3. Dissimilarity index (DI) of distribution of human resources of healthcare system, 2007-2013.

\begin{tabular}{|l|l|l|l|l|l|l|l|}
\hline & Specialists & General practitioners & Pharmacists & Paramedics & Dentists & Nurses & Behvarzes \\
\hline 2007 & 36.95 & 33.26 & 14.16 & 27.08 & 23.9 & 28.45 & 23.79 \\
\hline 2008 & 39.33 & 28.56 & 22.01 & 28.45 & 23.64 & 26.88 & 20.36 \\
\hline 2009 & 37.69 & 31.11 & 25.87 & 30.82 & 22.37 & 30.08 & 23.36 \\
\hline 2010 & 25.48 & 9.33 & 16.17 & 17.11 & 7.7 & 25.1 & 29.22 \\
\hline 2011 & 26.14 & 8.21 & 15.19 & 16.41 & 7.11 & 24.7 & 15.74 \\
\hline 2012 & 27.22 & 8.73 & 13.68 & 18.34 & 12.04 & 26.27 & 37.12 \\
\hline 2013 & 26.64 & 8.72 & 11.32 & 18.08 & 14.02 & 25.73 & 20.74 \\
\hline Mean & 31.35 & 18.27 & 16.91 & 22.32 & 15.82 & 26.74 & 24.33 \\
\hline SD & 6.27 & 11.96 & 5.14 & 6.17 & 7.4 & 1.92 & 6.96 \\
\hline Min & 25.48 & 8.21 & 11.32 & 16.41 & 7.11 & 9.5 & 15.74 \\
\hline Max & 39.33 & 33.26 & 25.87 & 30.82 & 23.9 & 24.79 & 37.12 \\
\hline
\end{tabular}

Table 4. Time trend analysis of inequality in human resources in healthcare sector in Tehran Province, 2007-2013

\begin{tabular}{|l|l|l|l|l|l|l|}
\hline Variable & $\beta$-coefficient & S.E. & t statistics & $\mathrm{p}$-value & $\mathrm{R}^{2}$ & Prob $>$ Chi $^{2}$ ( Breusch-Pagan) \\
\hline Specialists & 0.006 & 0.003 & 1.90 & 0.115 & 0.42 & 0.287 \\
\hline General practitioners & 0.004 & 0.001 & 4.54 & 0.006 & 0.80 & 0.455 \\
\hline Pharmacists & 0.004 & 0.002 & 1.62 & 0.166 & 0.34 & 0.297 \\
\hline Paramedics & 0.006 & 0.003 & 2.11 & 0.089 & 0.47 & 0.313 \\
\hline Dentists & 0.005 & 0.003 & 1.54 & 0.185 & 0.32 & 0.309 \\
\hline Nurses & 0.006 & 0.005 & 1.23 & 0.274 & 0.23 & 0.283 \\
\hline Behvarzes & -0.013 & 0.013 & 0.97 & 0.377 & 0.35 & 0.809 \\
\hline
\end{tabular}

\section{Discussion}

Since one of the main objectives of the development plan in the health system in Iran is the establishment of justice to access health services and the appropriate distribution human resources in the sector, also the first step for equitable access to health care services in all countries is equitable distribution of human resources, monitoring the allocation of resources will be necessary according to inequality indices. As the results of this study show, the inequality in the distribution has increased by increasing the educational levels of human resources so that the highest and the lowest inequality in the distribution of health sector belongs to specialists (as the highest level of education) and Behvarz (as the lowest level of education in Iran's health system), respectively. The results of a similar study showed that the distribution of specialists, general practitioners, dentists, pharmacists, and paramedics in Kermanshah Province (in western Iran) was better than our estimate for Tehran Province (26). Evaluating the trend of changes in human resources during the study showed that inequality in the distribution of human resources was increased, it is worth mentioning that there are various factors for the reduction of inequality in the distribution of human resources that may affect the allocation of human resources in the health sector, with the two most important categories of them as follows. The first category is the demographical and geographical structure of each region so that the more developed regions in terms of socio-economic standards are more easily able to attract human resources with higher educational 
levels. The results of the present study also showed that the level of expertise, and consequently the educational level of human resources, was reduced by moving from Tehran as the capital towards less populated cities, such as Islamshahr (reducing the number of specialists and increasing the number of Behvarz). The rate of development was considered to be the most important factor in the distribution of human resources by previous studies, such as Nasirpour et al. and Alam et al. in Bangladesh (4, 27). The second category is the structure of the service system (the center of the service provider organizations) and the urban structure of each region. Different hospitals, imaging centers, and reference laboratories can be considered as examples of the service system, and the economic, social, and cultural situation of each area can be mentioned in the field of urban structures. It should be noted that there is a positive relationship between working forces and available infrastructure in each geographical unit. Several studies, including Shahabi et al.'s and Nasiripour et al.'s studies showed that there was a direct relationship between the distribution of healthcare resources and distribution of specialists and nurses $(4,28)$. Various studies also have indicated that the status of socio-economic indices, the quality of living standards, and income levels have an important role in the establishment of physicians in each region $(29,30)$. After considering the above factors, it is obvious that a part of the inequality of the distribution of human resources can be solved through demographic factors and available infrastructure in the different cities of Tehran Province. Moreover, one of the essential steps for an equitable distribution of human resources is the socio-economic factors of the various regions of the Province. This study had some strengths and some weaknesses. In this study all the human resources of health sector were considered, and the status of their distribution in recent years was determined in the cities of Tehran Province. Furthermore, the necessary amount of redistribution required to achieve equality in the allocation of resources was determined in this study. Data for this study were collected from the Statistical Center of Iran (SCI), which is official data center of country, but there are some factors related to data that may influenced on the results, such as possible errors in the data gathering and the difference in the quality of data that were collected during the years of study via SCI.

\section{Conclusions}

The results showed that have been inequalities in the distribution of resources in the health sector in Tehran Province for the last few years and over time, these inequalities have been increasing, and all human resources of the health sector have attained a more unfair distribution. Given this situation and by developing the private sector and considering the willingness of this sector to operate in the more developed regions, it seems health policy makers should continually evaluate the distribution and the allocation of resources, and they should develop a specific plan for the allocation of human resources in the health sector.

\section{Acknowledgments:}

This paper was extracted from related research that was funded by Tehran University of Medical Sciences (fund number: 93-03-27-26018). Therefore, the authors thank the Deputy of Research of Tehran University of Medical Sciences.

\section{Conflict of Interest:}

There is no conflict of interest to be declared.

\section{Authors' contributions:}

S. Emamgholipour Sephiddashti, M. Arab and A. Kazemi Karyani designed the study. A. Kazemi Karyani, S. Ghazanfari, S. Rezaei and Z. Kazemi gathered data, analyzed and interpreted them. All authors had contribution in drafting the article and revising it critically. Also, all authors read and approved the final manuscript.

\section{References:}

1) Goodman RA, Goodman LP. Some management issues in temporary systems: A study of professional development and manpower-The theater case. Admin Sci Q. 1976: 494-501.

2) Zandian H, Giyasvand H, Nasimi Dost R. Measure of inequality in the distribution of health care resources: A Case study. Payesh. 2012; 11(3): 799-805.

3) Ketabforosh B, Fard Shah H, Jafari P, Khanlo K. Analysis of human capital development and health expenditures on labor productivity, International Conferences on Management, Chalanges and Solutions; Shiraz, 2013. Available from: www.civilica.com/0576.html.Paper-ICMM01-ICMM01

4) Nasiripour AA, Maleki MR, Tabibi SJ, Ehsani Chimeh E. Factors Influence on Geographic Distribution of Physicians in Selected Countries: A Review Article. J Kermanshah Univ Med Sci. 2013; 17(9): 600-10.

5) Bloor K, Maynard A, Hall J. Planning human resources in health care: towards an economic approach: an international comparative review: Canadian Health Services Research Foundation; 2003. 
6) Kabene SM, Orchard C, Howard JM, Soriano MA, Leduc R. The importance of human resources management in health care: a global context. Hum resour health. 2006; 4(20): 1-17. doi: 10.1186/1478-44914-20. PMCID: PMC1552082.

7) Tofighi S, Maleki MR, Shahabi M, Delpasand M, Nafis A. Distribution of Specialized Physicians and Active Beds in the Iranian Government Hospitals between 2001 and 2006. J Sch Public Health Inst Public Health Res. 2010; 8(3): 1-10.

8) Munga MA, Maestad O. Measuring inequalities in the distribution of health workers: the case of Tanzania. Hum Resour Health. 2009; 7(1): 4. doi: 10.1186/1478-4491-7-4. PMID: 19159443, PMCID: 2655278.

9) Kazemi Karyani A, Kazemi Z, Shaahmadi F, Arefi Z, Ghazanfari S. Determining Inequality and Trend of Geographic Accessibility to Pediatricians in Iran: 2007-2013. International Journal of Pediatrics. 2015; 3(21): 51-8.

10) Kiadaliri AA, Najafi B, Haghparast Bidgoli H. Geographic distribution of need and access to health care in rural population: an ecological study in Iran. Int J Equity Health. 2011; 10(1): 39-48. doi: 10.1186/14759276-10-39. PMID: 21939511, PMCID: PMC3196912.

11) Mobaraki H, Hassani A, Kashkalani T, Khalilnejad R, Chimeh EE. Equality in distribution of human resources: the case of Iran's Ministry of Health and Medical Education. Iran J Public Health. 2013; 42(1): 161. PMID: 23865035, PMCID: PMC3712591.

12) Mirsaeid G, Javad S, Mirzaie M, Haghshenas E, Dargahi H. Human resources distribution among Tehran university of Medical Sciences Hospitals. Payavard Salamat. 2014; 7(5): 432-46.

13) Statiatical Center of Iran. Available from: http://www.amar.org.ir/.

14) Culyer A. The Dictionary of Health Economics 2ed, editor: Edward Elgar Publishing Limited. 2010.

15) Karyani AK, Azami SR, Rezaei S, Shaahmadi F, Ghazanfari S. Geographical distribution of gynecologists and midwives in Kermanshah province (2008-2013). J Kermanshah Univ Med Sci. 2015; 19(5): 294-302.

16) Rodríguez JG, Salas R. The Gini coefficient: Majority voting and social welfare. JET. 2014; 152: $214-23$. doi: 10.1016/j.jet.2014.04.012.

17) Okamoto M. Interpolating the Lorenz Curve: Methods to Preserve Shape and Remain Consistent with the Concentration Curves for Components. Rev Income Wealth. 2014; 60(2): 349-84. doi: 10.1111/roiw.12083.

18) Bandos AI, Guo B, Gur D. Jackknife variance of the partial area under the empirical receiver operating characteristic curve. Stat Methods Med Res. 2014. doi: 10.1177/0962280214551190. PMID: 25228637.

19) Ma C, Huang S, Zhou Y. Measuring Inequalities in Gene Co-expression Networks of HIV-1 Infection Using the Lorenz Curve and Gini Coefficient. J Data Mining Genomics Proteomics. 2014; 5(148): 2153-602.

20) Bellu LG, Liberati P. Charting Income Inequality, The Lorenz Curve, University of Urbino. Institute of Economics, Urbino, Italy. 2005.

21) Karagiannis E, Kovacevic M. A method to calculate the Jackknife variance estimator for the Gini coefficient. Axford B Econ Stat, 2000; 62(1): 119-22. doi: 10.1111/1468-0084.00163.

22) Fontana R, Rapallo F, Rogantin MP. Two-Factor Saturated Designs: Cycles, Gini Index, and State Polytopes. J Stat Theory Pract. 2014; 8(1): 66-82. doi: 1080/15598608.2014.840518.

23) Wager S, Hastie T, Efron B. Confidence intervals for random forests: The jackknife and the infinitesimal jackknife. J Mach Learn Res. 2014; 15: 1625-51. PMID: 25580094, PMCID: PMC4286302.

24) Shao J, Wu CJ. A general theory for jackknife variance estimation. Ann Stat. 1989: 1176-97. doi: $10.1214 / \mathrm{aos} / 1176347263$.

25) Mafimisebi T, Oguntade A, Fajemisin A, Aiyelari O. Health infrastructure inequality and rural urban utilization of orthodox and traditional medicines in farming households: A case study of Ekiti State, Nigeria. Health Management-Different Approaches and Solutions. 2011: 197-214.

26) Rezaei S, Karyani AK, Fallah R, Matin BK. Relative inequalities in geographic distribution of health care resources in Kermanshah province, Islamic Republic of Iran. East Mediterr Health J. 2016; 22(1).

27) Alam GM. The role of science and technology education at network age population for sustainable development of Bangladesh through human resource advancement. Sci Res Essays. 2009; 4(11): 1260-70.

28) Shahabi M, tofighi S, Maleki M. The Nurse and Specialist Physicians Manpower Distribution by Population and Its Relationship with The Number of Beds at Public Hospitals in Iran's; 2001-2006. Journal of Health Administration. 2011; 13(4): 8-15.

29) Landon BE. Career Satisfaction among Physicians. JAMA. 2004; 291(5): 634. doi: 10.1001/jama.291.5.634. PMID: 14762046.

30) Astor A, Akhtar T, Matallana MA, Muthuswamy V, Olowu FA, Tallo V, et al. Physician migration: views from professionals in Colombia, Nigeria, India, Pakistan and the Philippines. Soc Sci Med. 2005; 61(12): 2492-500. doi: 10.1016/j.socscimed.2005.05.003. PMID: 15953667. 